\title{
Smart controller design for safety operation of the MEA electrical distribution system
}

\author{
Cosimo Spagnolo, Sharmila Sumsurooah, Christoper Ian Hill, Member, IEEE, Serhiy Bozhko, Member, IEEE \\ University of Nottingham \\ Power Electronics and Machine Control, PEMC \\ Nottingham, United Kingdom \\ ezzcs2@nottingham.ac.uk
}

\begin{abstract}
-as the electrical network of the future aircraft becomes more and more complex, there is a need to develop a smart controller that can enable fast and automatic decisions to be taken to protect the vital operations of the system. This work aims to show how a control strategy can be devised to ensure the safe operation of such an electrical power system (EPS). The case study presented in this paper demonstrates how a smart controller can be used to ensure the uninterrupted power supply to the high priority loads in the event of the failure of one to four power electronic converters. The control logics are developed using the finite state machine (FSM) method, and applied to a representative DC based EPS of the future aircraft. The results are verified in Simulink environment.
\end{abstract}

Keywords-MEA, AEA, Aircraft Electric Power System, HV270DC, Smart Network, Finite state machine

\section{INTRODUCTION}

There has been a rapid evolution in the electrical power capacity of the aircraft in the recent years. The Boeing 787 Dreamliner[1] with its electrical power system (EPS) of more than $1 \mathrm{MW}$ and the fast trend towards the More Electric Aircraft (MEA) have brought new advancements in the aviation's history[2]. A key aspect of the MEA concept is that traditional pneumatic and hydraulic loads are replaced by electrical equivalents. The electrical systems have led to important improvements in the aircraft power system particularly due to the extensive use of power electronic technologies. The EPSs have higher reliability, controllability, efficiency; they are easier to replace or maintain and have lower carbon emissions [3, 4]. However, the safety issues as well as the potential of system optimisation related with electrification need to be further investigated. Extensive research is ongoing in this field, starting from studies on the fault tolerant, high power density electrical machines for electrical power sources application[5] to the new Dual Active Bridge converters (DAB) that can provide better solutions in terms of reliability and capability under bidirectional operations[6]. This paper addresses the safety of the MEA EPS. Moreover, studies on the use of either AC or DC type of the electrical system may play a key role in determining the next step towards the All Electric Aircraft (AEA). Recent studies have demonstrated the benefits of the high voltage DC systems (HV270DC). With DC systems, problems such as the skin effect can be eliminated and the performance of cables can be increased as shown in [7]. Further, the use of rectifier devices for the electrical instrumentations such as radars[3] will no longer be required, thus leading to reduction of weight of the power system. This work is applied to a representative aircraft DC based electrical network. A fundamental step in the development of the aircraft EPS is to enable all the electrical devices on board to work at the safest and most optimal level. For instance in order to ensure high availability of electric power within the aircraft, the power network architecture should allow a potential redundancy of the certain power supplies as well as critical devices such as power converters. Vital loads should be powered under both normal and fault conditions. Energy storage systems, along with suitable power electronic interfaces, can provide a wide array of solutions to such key issues. The EPS can be designed to be have various energy configurations[8]. The electrical network can be managed, optimised and ensured safe under different operating conditions, and critical fault scenarios by using a smart controller.This paper develops a smart controller that manages the power flow in the EPS under critical fault scenarios of its power electronic devices, with the aim to ensure continuous power supply to the vital loads during these fault conditions. There are different ways to design the EPS controller, "C language", Fuzzy logic and Finite State Machine (FSM), as reported in previous studies in [8-10], as will be further discussed in section III in this paper. In this work, the controller is based on FSM theory. The FSM is a computational model, where the behaviour of the system can be modelled as a set of states and transitions[11]. There are advantages that are considered in the use of FSM for the design of the controller. First, it is easy to use due to the fact that it is a graphical language. Second, it contains fast and powerful algorithms[12]. The work in this paper is divided in six sections. Section II discusses how the power flow can be managed in the aircraft EPS. Section III outlines the methods that can be used to design the controller as reported in the literature and introduces the theoretical background of the FSM method that is used in this paper. Section IV presents a case study whereby a control strategy is developed for the design of the smart controller to ensure the uninterrupted power supply to vital loads in a representative MEA EPS in the event of faults in the power electronic converters. Section V implements the control approach to the representative EPS in the Simulink environment and discusses the results of the case study. The conclusion is presented in the section VI. 


\section{POWER MANAGEMENT OF THE AIRCRAFT EPS}

The configuration of a conventional EPS for modern aircraft is shown in Figure 1. The EPS is supplied by $115 \mathrm{~V}$ line to neutral AC voltage with a line frequency of $400 \mathrm{~Hz}$. With this configuration the electrical generators are connected to the main engines (in most cases each engine supplies two generators) via a mechanical drive[4], which is used to keep the mechanical speed and the electrical frequency constant on the electric bus. These are the primary electrical power sources.

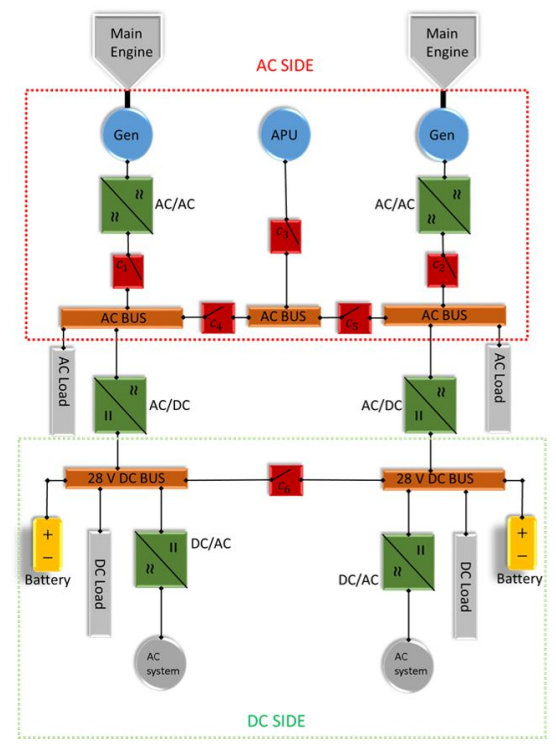

Fig. 1. Typical EPS of a conventional aircraft

The generators supply power to a set of ac loads through dedicated AC buses. These loads can be an induction motor driving a hydraulic pump or lighting. There are multiple buses in the aircraft to account for redundancy and for use during emergency operations. The AC buses deliver power to the DC buses through transformer rectifier units (TRU) as shown as AC/DC converters in Fig. 1. The $28 \mathrm{~V} \mathrm{DC}$ buses are used for supplying the avionics systems on-board. In the new generation of aircraft such as Boeing 787 and Airbus A380 the variable speed constant frequency (VSCF) is replaced by variable frequency bus, which requires the power conversion for supplying different types of loads but introduces the advantage of operating motors at different speed so as to work at the optimal point. DC-DC power conversion is also needed for devices such as battery chargers [1]. While standard topologies for electric power systems are already complex, the nextgeneration aircraft EPSs are expected to become even more elaborate, making the design of such architectures more challenging. A step forward in the design of the EPS of the future aircraft is the use of HV270DC systems. An example of such a configuration is depicted in Figure 2. In the design of military aircraft and unmanned aircraft, HVDC systems are already used in order to cope with the high power demand of the system. The main idea is the use of an increased DC voltage, typically $270 \mathrm{~V}$ $\mathrm{dc}$, which is obtained from the conversion of $115 \mathrm{VAC}$ through a transformer rectifier unit. The F-22 and F-35 both currently utilise HVDC[13]. There are two main advantages in the use of higher voltage level. First, it is possible to obtain $270 \mathrm{~V} \mathrm{dc}$ from a conventional generator, by means of a transformer rectifier unit. Second, some equipment such as radars and direct actuator controllers, which are powered from $115 \mathrm{Vac}$, have integrated blocks of rectification, that convert the $115 \mathrm{Vac}$ levels to $270 \mathrm{Vdc}$; this can result in the reduction in system weight.

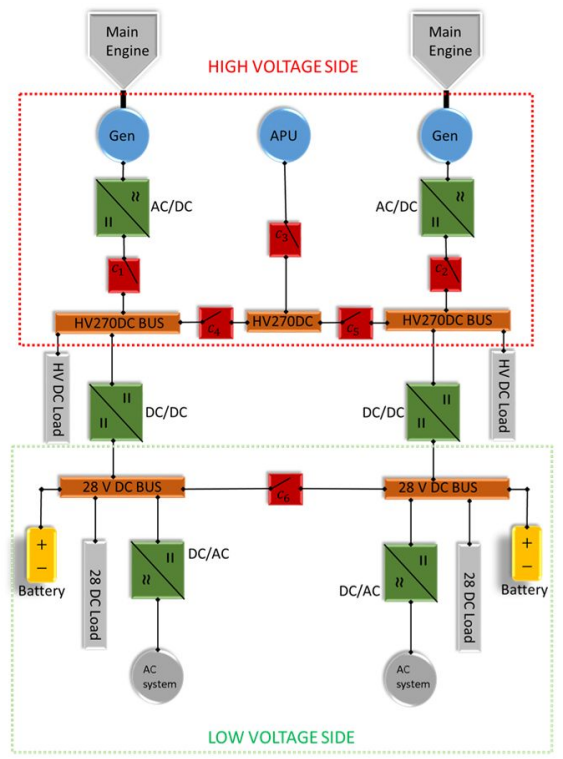

Fig. 2. An example HV270DC EPS for the future aircraft

In both configurations shown in Fig. 1 and 2, the buses are connected by tie-breakers, which are electromechanical devices for commutations of the EPS. These switches, labelled as $c_{1}$ to $c_{6}$ in Fig. 1 and 2, are used to control the flow of power and reconfigure the topology of the electric power system by establishing new connections between components. Changing the status of the contactors (open or closed) will result in different system configurations and will thereby affect the power level of different buses or loads. For instance, in the case of a generator failure, an auxiliary power unit (APU) or battery may be used to power some emergency buses to allow the safety critical operations. It is possible to devise a strategy for a controller such that it manages the power flow distribution by acting on the switches $c_{1}$ to $c_{6}$ setting new power paths and ensuring safe operation under different operating scenarios. In this paper, the control strategy is designed to help the main generators in the critical phases and supply the vital load in all the possible fault scenarios. Multiple approaches may be employed to design such a controller. The next section discusses the latter methods along the FSM which is the method adopted in this paper.

\section{THEORETICAL BACKGROUND}

For managing the EPSs through the use of a smart controller, it is important to identify the main objectives that the controller must accomplish and to define the corresponding rules that will enable the controller to carry out these functions. For instance the aim of the controller can be to provide uninterrupted power to a specified bus or load. In order to achieve such a goal, the controller can be given the tasks to reconfigure the system by switching on or off of a number of the contactors, based on the reconfiguration strategy[14]. However, rules must be established to avoid dangerous conditions such as creating 
parallel power paths between two sources or discharging the batteries below a pre-set limit. The reconfiguration strategy is used to find the correct pathway to feed each load while taking into account the optimisation of the system in terms of power flow and avoiding unsafe configurations. Different methodologies for the controller design of the power system have been investigated in the recent years. As the EPSs for the future aircraft are becoming more intricate, the strategies for the controller are becoming more complex; the controller has to become smarter. Starting from the use of the $\mathrm{C}$ language, the methods are moving towards more intelligent programming languages like "C Language Integrated Production System" (CLIPS)[10]. These type of languages are used in the Knowledge-based system, which consist in the implementation of business and mandatory rules in a single framework. The basic structure of rule is made of two main parts, which consist of a condition part (IF) and action part (THEN). Whenever all the rule's conditions are fulfilled, the rule is satisfied. The main strength of the knowledge based system is its capacity to activate the rules whenever the conditions are fulfilled. Whereas this capacity is not provided in traditional procedural programming where conditions of an "if" test are evaluated at a particular point of the program. The priority level of each execution can be specified to each rule, so if several rules can be fired at the same time, the highest priority rule will be fired first[14]. Since the controller must be able to operate on the EPS applying a set of specific rules, these rules need to be expressed ("synthetized") in a mathematical language and translated for the processor. A first approach about synthesis of reactive systems can be found in $[15,16]$. Moreover, due to the fact that the EPS can be seen as a reactive system the rules cited above can be applied. The Linear Temporal Logic (LTL)[17] can also be considered a good solution to apply in order to satisfy all the requests in the management of the EPS. LTL is an extension of propositional logic that incorporates notions of temporal ordering to reason about correctness over a sequence of states. In reactive systems (i.e., systems which react to a dynamic, a priori unknown environment)[18], correctness will depend not only on inputs and outputs of a computation, but on execution of the system as well. Temporal logic is a formalism well-suited for these types of problems in which the system must react to an adversary or environment. This paper uses the FSM which combines "Knowledge-based method" and LTL notions. FSM can be considered a suitable tool for the design of the control logic. Basically, FSM is a computation model that can be implemented with hardware or software and can be used to simulate sequential logic. FSM can be used to model problems in many fields including mathematics and artificial intelligence. In a FSM the behavior of the system can be modelled as a set of states and transitions between states, these systems are known as reactive systems[11]. In mathematical notations, the FSM can be expressed as:

$$
f\left(\sum, S, s_{0}, \delta, F\right)
$$

In equation (1), $\sum$ represents a finite set of symbols (as variables of the system), $S$ is a finite set of states, $s_{0}$ is the initial state, such that $s_{0} \in S$, and $\delta$ is a state transition function defined in equation (2) and $F$ is finite set of final states.

$$
\delta: S \times \sum \rightarrow S
$$

An example of the formulation (1) is depicted in Fig. 3.

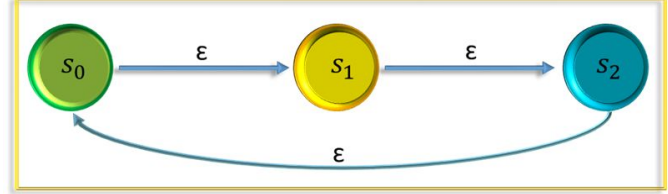

Fig. 3 Example of a reactive system

The following equations describe the system in Fig. 5

$$
\begin{aligned}
\sum & =[\varepsilon] \\
S & =\left[s_{0}, s_{1}, s_{2}\right] \\
\delta=\left[S_{0} / \varepsilon\right. & \left.\rightarrow s_{1}, s_{1} / \varepsilon \rightarrow s_{2}, s_{2} / \varepsilon \rightarrow s_{0}\right] \\
F & =s_{2}
\end{aligned}
$$

The FSM approach is applied to the case study in section IV of this paper.

\section{CASE STUDY}

This section develops a controller which has the main task to ensure the uninterrupted power to the vital loads under fault conditions based on the Finite State Machine (FSM). The controller strategy is tested and validated in simulation in the Simulink environment.

\section{a) Aircraft EPS model}

The study is demonstrated by applying it to an example EPS of a future aircraft as shown in Fig. 4.

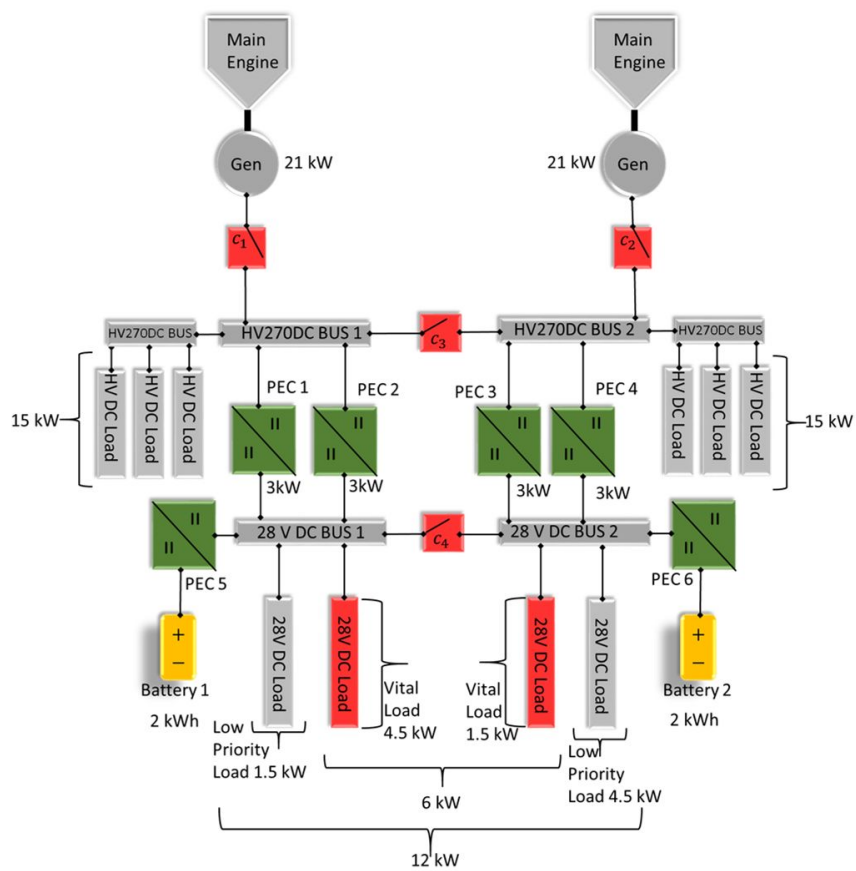

Fig. 4. Circuit diagram of the EPS under study 
The electrical network shown in Fig. 4 is a good example of the MEA concept with a HV270DC system. It is composed of two main generators of $21 \mathrm{~kW}$ each. These generators provide power to two sets of high voltage (HV) loads of $15 \mathrm{~kW}$ each through two HV270DC buses, and four sets of low voltage (LV) loads of $6 \mathrm{~kW}$ each through two LV28VDC buses. The two out of the four LV loads are vital high priority loads that require uninterrupted supply of power.The four DC/DC converters (PEC 1 to 4 ) rated at $3 \mathrm{~kW}$ each, are bidirectional, and allow power transfer between the low voltage and the high voltage side, thus increasing the availability of power in the entire EPS. These four converters can be controlled in order to adjust the power delivered from the generators to the loads. Of note is that the power converters are connected in couple between the $\mathrm{HV}$ bus and the LV bus as shown in Fig. 4. This design introduces redundancy in the power system, which is beneficial for managing fault conditions and power flow within the network. The low voltage side of the EPS consists of two batteries of $2 \mathrm{kWh}$ each, sized from commercial values[19]. They are connected to the low voltage buses through DC/DC converters, which are used to maintain the value of the bus voltage at 28 volt. It is to be noted that the devices of the electrical network in Fig. 4 have been modelled as ideal components in Simulink environment, as the focus of the study was to verify the logic operations of the controller.
The power converters are sized in order to transfer power to the low voltage side under the normal operations. In case of emergency such as the failure of one of more $3 \mathrm{~kW} \mathrm{DC/DC}$ power electronic converters, the battery can be employed to supply the surplus of requested power, especially to the vital loads. This can be achieved by designing a smart controller as will be discussed in the next section.

\section{B. The control strategy}

The controller is designed to ensure the safe operation of the EPS by supplying uninterrupted power to the two vital $6 \mathrm{~kW} \mathrm{LV}$ loads under a number of fault scenarios consisting of the failures of one up to four of the $3 \mathrm{~kW} \mathrm{DC/DC} \mathrm{converters.} \mathrm{Tables} \mathrm{I} \mathrm{depict}$ a set of actions that the controller has to perform when one or more power electronic converters fail. The possible configurations, identified as 16 states as shown in Table I to IV, are dependent on the state of charge of the two batteries when the fault occurs. Table I shows the required actions under normal conditions. Tables II, III and IV show the actions to be initiated in case of failures of one, two and three/ four power electronic converters respectively. Depending on the state of the batteries and fault scenarios, the controller will act on the power converters, batteries and the switches to modify the power paths configurations of the EPS to ensure uninterrupted power flow to the vital loads, as described in Tables I to IV. The next section shows how the system changes configuration after the failure of one to four of the $3 \mathrm{~kW}$ power electronic converters in simulation
Table I

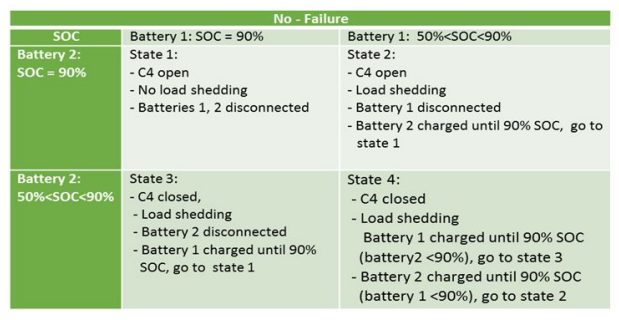

Table III

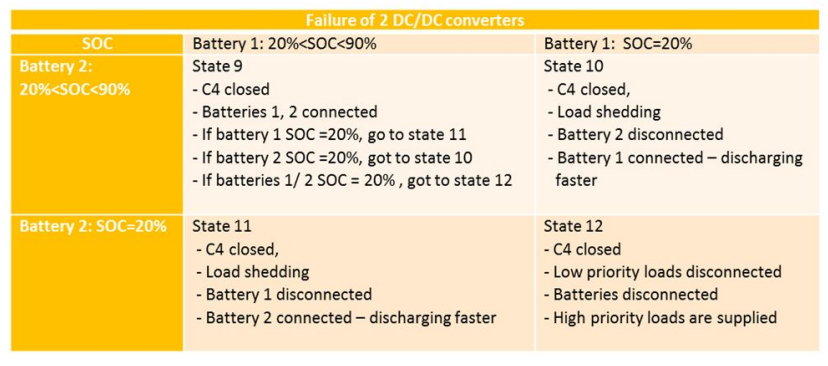

Table II

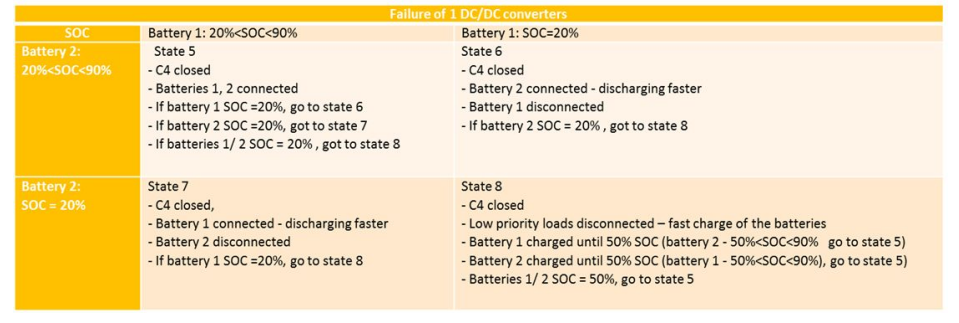

Table IV

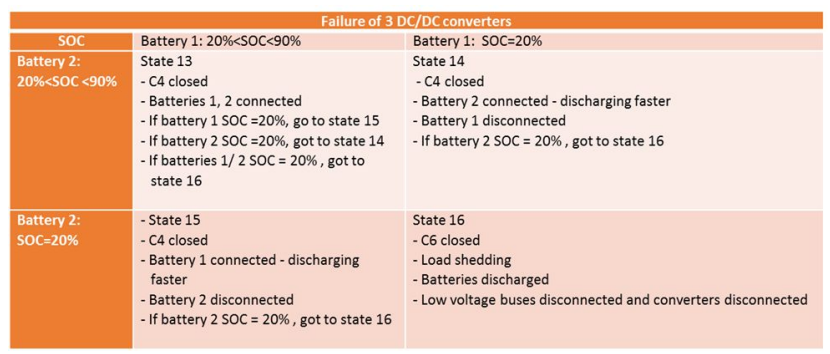




\section{SiMULATIONS AND RESULTS}

This section applies the control strategy outlined in section IIIB to the EPS depicted in Fig. 4 by using the FSM that has been explained in section III. The simulations are performed in Simulink environment.

\section{(a) Normal condition of operation}

During normal condition, the state of charge of the batteries are maintained at $90 \%$, as described in the state space table I and the state flow diagram in Fig. 5.

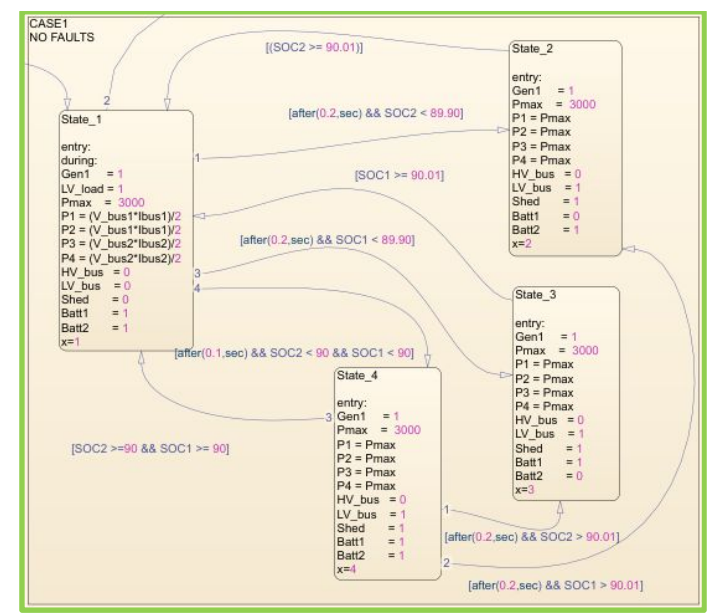

Fig. 5. No-fault scenario: State space diagram

The Fig. 5 shows the source code with the configuration of the states 1 to 4. Each state is defined inside the blocks in Fig. 5 while the arrows define the conditions to transition from one state to another. So, each state refers to a different configuration of the system. The main parameters used in the state diagram are defined next. Of note is that when the value assigned to the contactor is " 1 ", it is open and when the value is " 0 ", it is closed. $L V_{\text {load }}$ represents the contactor used to connect $\left(L V_{\text {load }}=1\right)$ or disconnect $\left(L V_{\text {load }}=0\right)$ the non-essential load on the low voltage side. $P_{\max }$ represents the maximum power that can be transferred through one power electronic converter. Batt ${ }_{1}$ and Batt $_{2}$ represent the commands used to connect or disconnect the batteries 1 and 2 respectively. $P_{1}, P_{2}, P_{3}, P_{4}$ represent the power that are transferred through the power electronic converter PEC 1, 2, 3 and 4 respectively, and are calculated based on the bus voltage $V_{B u s}$ and the bus current $I_{B u s}$ of the low voltage side. The contactor that connects the two HV buses is called $H V_{\text {bus }}$ and acts on contactor $\mathrm{C} 3$ in Fig. 4 . The contactor that connects the two $\mathrm{LV}$ buses is called $L V_{b u s}$ and acts on contactor C3 in Fig 4. The variable Shed is used to shed the power of the low voltage load, while the variable $x$ is used to verify the state in which the system is working. Figs. 6 to 8 depict the simulation results under the no-fault scenario. From Fig. 6, it can be seen that the SOC of battery 1 (SOC1) and battery 2 (SOC2) are below $90 \%$ at the beginning of the simulation to $\mathrm{t}=260 \mathrm{~s}$; the system is in state 4 . Between $260 \mathrm{~s}$ and $317 \mathrm{~s}$, the SOC1 is $90 \%$ while SOC2 is below $90 \%$; the system is in state 3 . When the system is in states 4 and 3 , the controller sheds the low priority loads, which consist of $1.5 \mathrm{~kW}$ on LV bus2, as is depicted in Fig. 8, and another $1.5 \mathrm{~kW}$ on LV bus1. The power thus made available from load shedding is used to charge the batteries. The system transitions to state 1 after time $\mathrm{t}=317 \mathrm{~s}$ when the batteries are charged to $90 \%$. The voltage on the buses is kept constant at $28 \mathrm{~V}$ in all states, as shown in Fig. 8 .

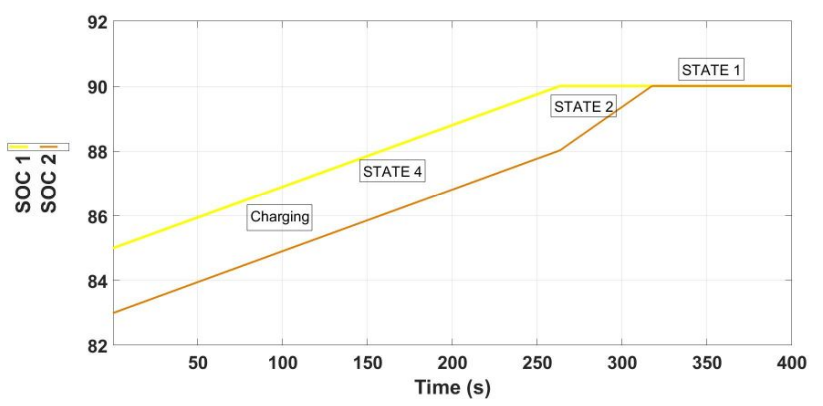

Fig. 6. No-fault scenario: states of charge of battery 1 and battery 2

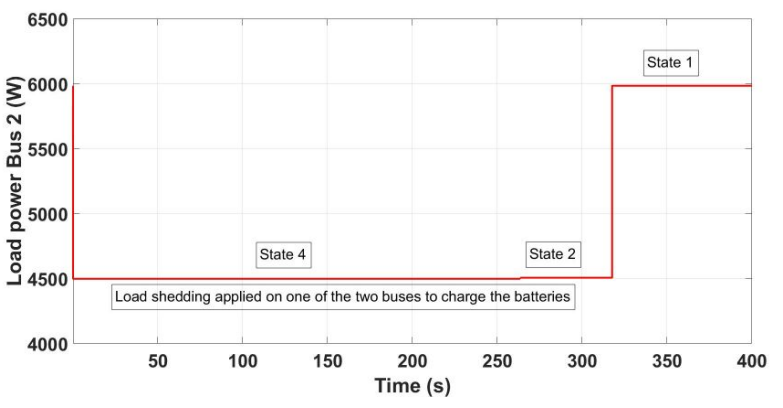

Fig. 7. No-fault scenario: Load shedding of $1.5 \mathrm{~kW}$ from $L V$ bus 2 from $\mathrm{t}=0 \mathrm{~s}$ to $\mathrm{t}=317 \mathrm{~s}$ (and $1.5 \mathrm{~kW}$ from LV bus 1 which is not shown in Fig. 7)

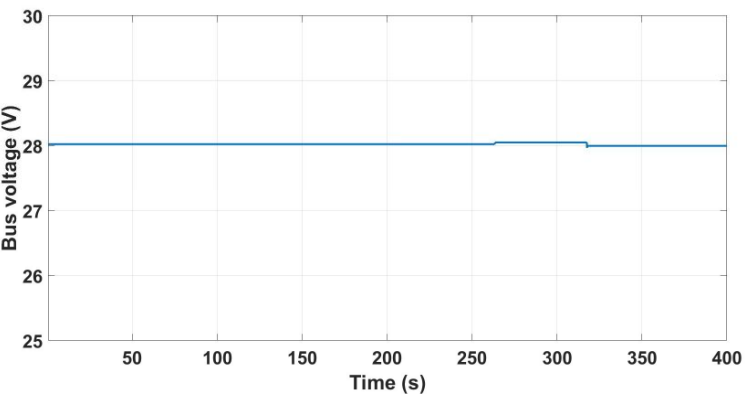

Fig. 8. No-fault scenario: Voltage maintained at $28 \mathrm{~V}$ on LV bus 2

\section{(b) Failure of one power electronic converter}

Fig. 9 shows the state transition diagram when the system is subject to the failure of one the power electronic converters (PEC 1). In this scenario, the system uses the remaining three converters to transfer maximum power to the loads. The $3 \mathrm{KW}$ power that can no longer be transferred through the faulty PEC1, is now supplied from the batteries. The batteries are used to supply all the LV loads until the SOC is below the minimum value of $20 \%$. When the SOC is $20 \%$, shedding is applied to the non-essential LV loads, and the surplus power thus available is used to recharge the batteries up to $50 \%$ as detailed in Table II. 


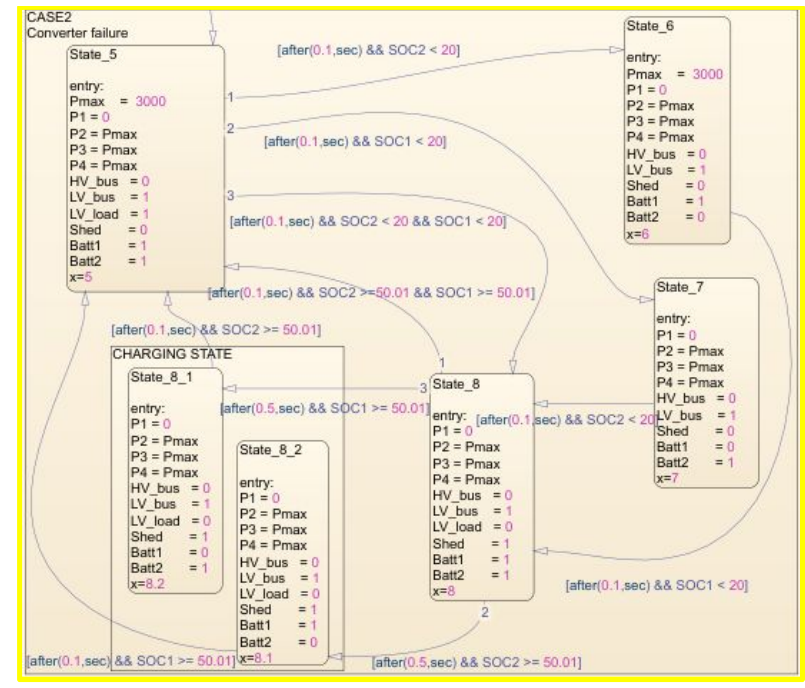

Fig. 9. State space diagram under failure of one power electronic converter

The Fig. 10 to 13 show the behaviour of the system after the fault in PEC1. After the failure of one converter which is shown in Fig. 10, the system starts using the batteries in order to supply the low voltage loads; the system thus transitions to state 5 as shown in Fig. 11. After the battery 1 is discharged, the controller disconnects it, and the system moves to state 7 where only the battery 2 is used, as depicted in Fig. 11. The system drains current from the batteries until the SOCs reach $20 \%$. For $3480 \mathrm{~s}$, the batteries are used to supply the low voltage loads, including the vital loads. Once the SOCs reach the minimum of $20 \%$, the controller moves the system to state 8 , as shown in Fig.11, disconnects the non-essential loads and start to charge the battery until SOC of the batteries are $50 \%$. It is to be noted that the sub-states 8.1 and 8.2 are used to charge one battery at a time. Once the system charges the batteries up to $50 \%$, the non-essential loads can be supplied again from the batteries as shown in Fig. 13 from time ( $t=5200$ s). Fig. 13 shows the plot of the load power on the bus 1 and bus 2 . The total power on bus 1 is $4.5 \mathrm{~kW}$ which consists of only the vital loads. The total power on bus 2 is $1.5 \mathrm{~kW}$ which also consists the vital loads on bus1. Note that the vital loads are always supplied during the operation. The bus voltage is maintained nearly constant at 28 $\mathrm{V}$, as the system states change, as can be seen in Fig. 13.

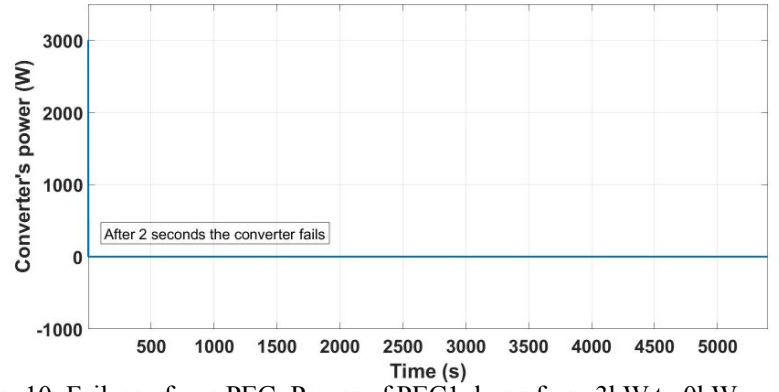

Fig. 10. Failure of one PEC: Power of PEC1 drops from $3 \mathrm{~kW}$ to $0 \mathrm{~kW}$

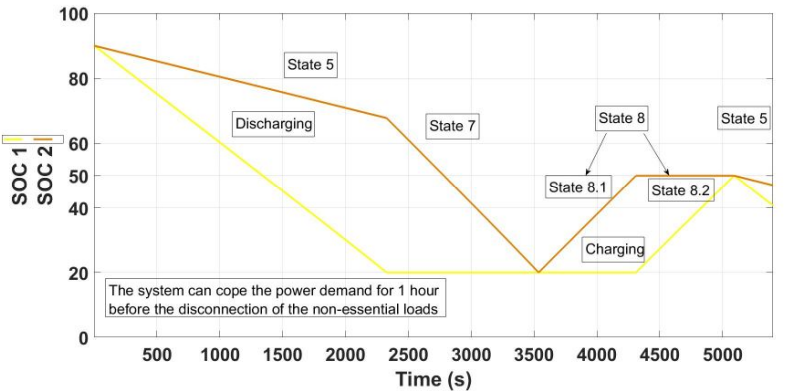

Fig. 11. Failure of one PEC: SOC of batteries 1 and 2

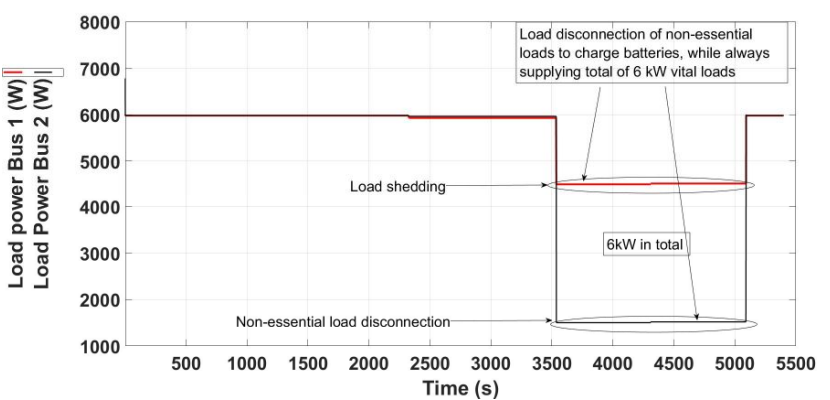

Fig. 12. Failure of one PEC: Load shedding of $1.5 \mathrm{~kW}$ on bus 1 and $4.5 \mathrm{~kW}$ on bus 2 , with uninterrupted power to the vital load of $4.5 \mathrm{~kW}$ on bus 1 and $1.5 \mathrm{~kW}$ from $\mathrm{t}=3500$ s to 5200 s

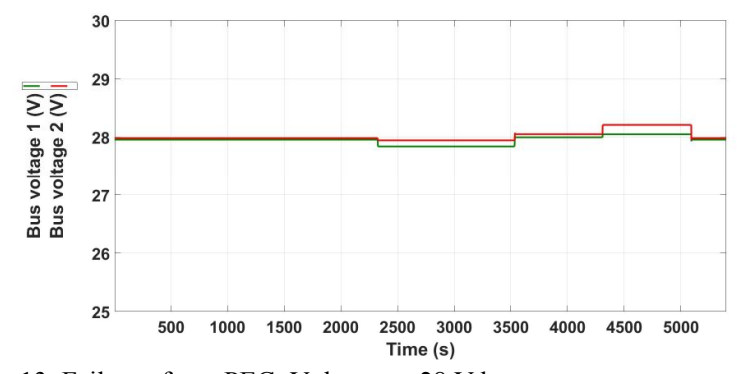

Fig. 13. Failure of one PEC: Voltage on $28 \mathrm{~V}$ buses

\section{(c) Failure of two power electronic converters}

The states of the system when two $3 \mathrm{~kW}$ power electronic converters fail are shown in Figure 14. The behavior of the system is detailed in the table III.

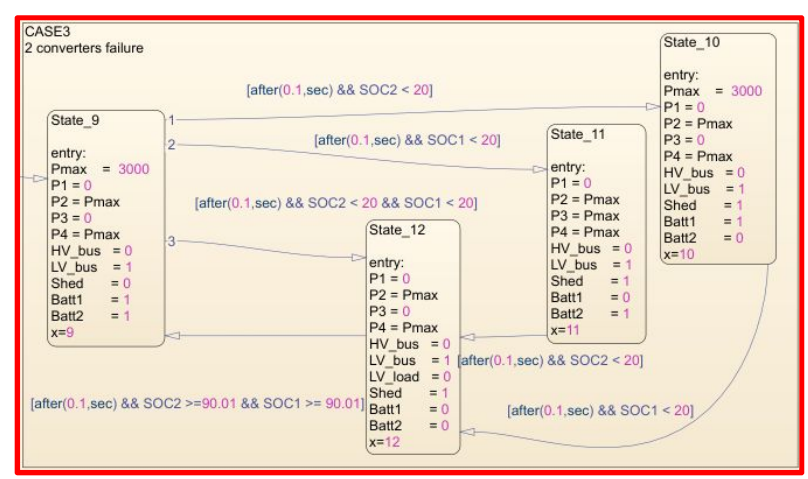

Fig. 14. Failure of two to four PEC: state space diagram

In the event of the failure of the two converters, the system transfers power to the low voltage buses through the remaining two healthy converters, and uses the batteries to provide the 
surplus power required to the low voltage loads; the system is in state 9. The behavior of the system under this critical failure of the two PEC is shown in Figs. $15-17$. The SOC of both batteries is $90 \%$ when the fault occurs; the system is in state 9 . The contactor $\mathrm{C} 4$ is closed. Both batteries supply the nonessential loads, which can no longer be supplied through the two faulty PEC. When the SOC of the batteries reach $20 \%$ at time $\mathrm{t}=1680$ s ( 28 mins), the batteries are not able to cope with the power demand as the SOC drops to $20 \%$. So the controller disconnects the non-essential loads. As can be seen in the Fig. 16 , once the SOCs are at $20 \%$, the system is in state 12 ; the system disconnects the non-essential loads $(1.5 \mathrm{~kW}$ on bus 1 and $4.5 \mathrm{~kW}$ on bus 2 ) and the two converters are used to supply the vital loads on the low voltage side (total of $6 \mathrm{~kW}$ ). The voltage is kept constant at $28 \mathrm{~V}$ during the transidtions between states as hsown in Fig. 17.

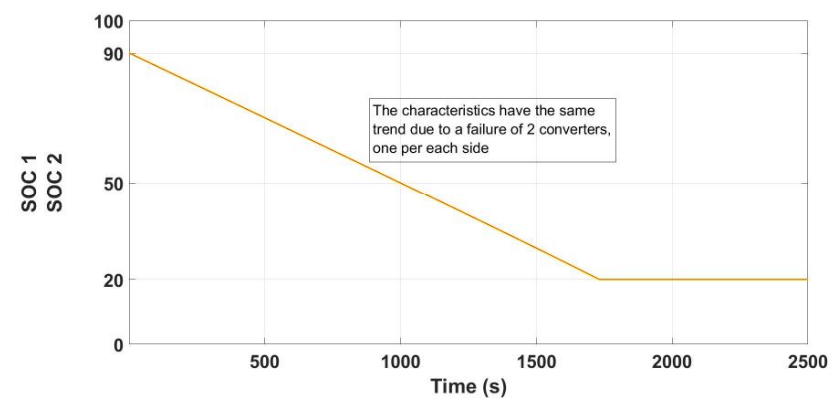

Fig. 15. Failure of two PECs scenario: SOC of batteries 1 and 2

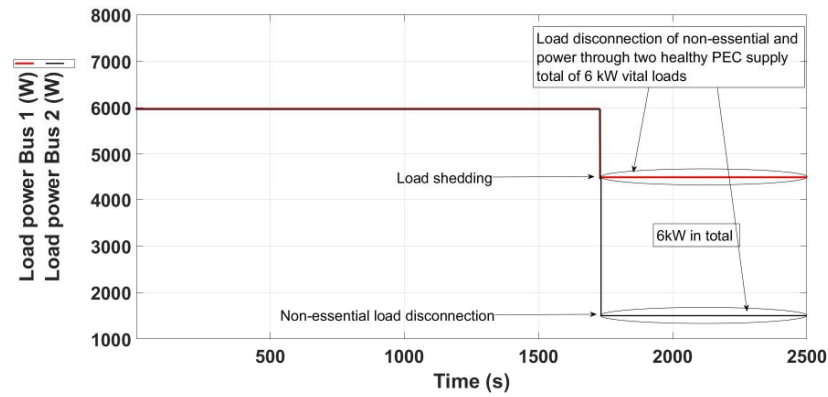

Fig. 16. Failure of two PECs: After 28 minutes the system disconnects the non-essential load of $1.5 \mathrm{~kW}$ on bus 1 and $4.5 \mathrm{~kW}$ loads on bus 2 . All power through healthy PECs supply the total vital loads of $6 \mathrm{~kW}$.

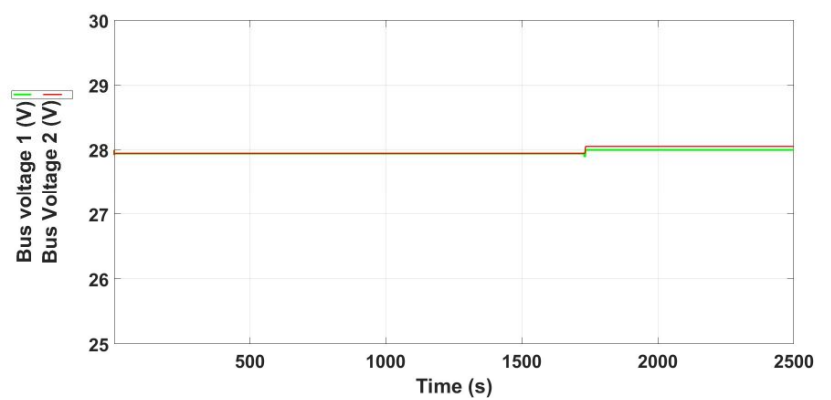

Fig. 17. Failure of two PECs: Voltage of the $28 \mathrm{~V}$ buses during all the operations

\section{(d) Failure of three to four power electronic converters}

Fig. 18 shows the states of the system in the event of the failure of three converters. The system states during the fault scenario is detailed in table IV.

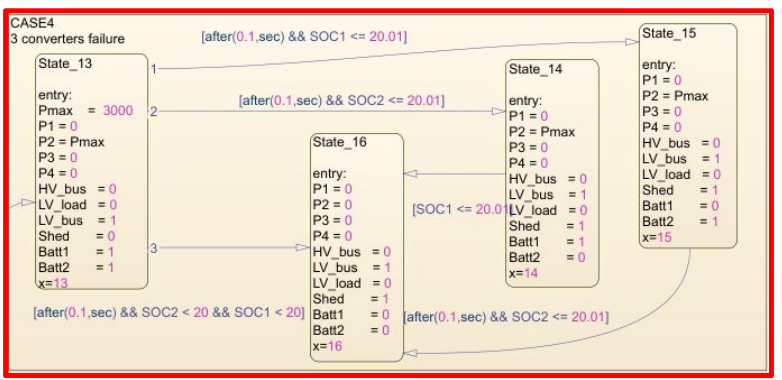

Fig. 18. Failure of three to four PEC: state space diagram

With the failure of a third converter, the controller uses the maximum power from the last healthy converter and the batteries to feed the low voltage high priority loads. The contactor $\mathrm{C} 4$ is closed. Shedding is applied to all the nonessential loads. As shown in Fig. 19, the total vital loads on LV side can be supplied for 28 minutes before the SOC of the batteries drop to $20 \%$; after this point, the healthy $3 \mathrm{~kW}$ PEC is used to supply only the $1.5 \mathrm{~kW}$ vital load. It is to be noted that if all four PECs fail, the batteries can supply the vital loads until their SOCs drop to $20 \%$, after which point, neither the $1.5 \mathrm{~kW}$ nor the $4.5 \mathrm{~kW}$ vital loads can be supplied as shown in Fig. 20. In actual systems, the fault scenarios of three or four PECs failing is less likely to happen. If such extreme fault scenarios are to be accounted for, other emergency actions can be included in the design.

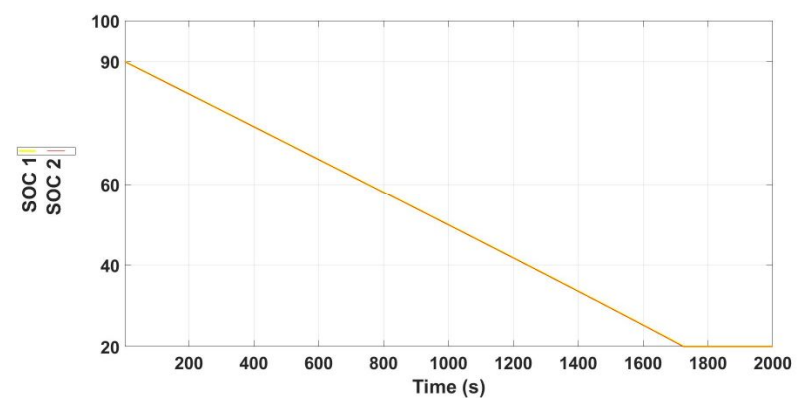

Fig. 19. Failure of three PECs: SOCs of batteries reach minimum of $20 \%$ after 28 minutes and cannot supply vital loads

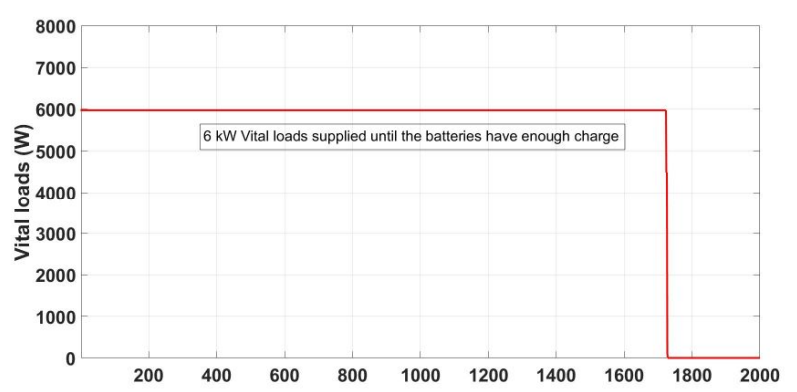

Fig. 20. Failure of fourth PECs: Power on $28 \mathrm{~V}$ bus 1 and bus 2, after 28 minutes all the loads on low voltage side are disconnected 


\section{CONCLUSION}

In this paper, the capability of a smart controller for the representative EPS of the future aircraft has been demonstrated. The strategy for the smart controller has been devised with the aim to provide uninterrupted power to low voltage high priority loads using FSM method. The control strategy has been implemented in Simulink and verified by considering faults scenarios involving the failure of one to four HV/LV DC/DC power electronic converters. The simulation results show that the controller activates the correct states such that the vital loads are always supplied for faults in up to two converters. For the unlikely event of three or four of power converters failing, the vital loads are supplied for a limited amount of time. Supplementary emergency actions can be taken into account if required by the design. This paper has shown how a smart controller can be designed to maintain the safe operation of an MEA electrical power system. As the electrical network of the future aircraft becomes more and more complex, the importance of having a smart controller is fundamental to enable fast and automatic decisions to be taken to protect the vital operations onboard.

\section{ACKNOWLEDGMENT}

This work is funded by the INNOVATIVE doctoral programme. The INNOVATIVE programme is partially funded by the Marie Curie Initial Training Networks (ITN) action (project number 665468) and partially by the Institute for Aerospace Technology (IAT) at the University of Nottingham.

\section{REFERENCES}

B. Sarlioglu and C. T. Morris, "More Electric Aircraft: Review, Challenges, and Opportunities for Commercial Transport Aircraft," IEEE Transactions on Transportation Electrification, vol. 1, pp. 5464, 2015.

[2] I. Moir and A. Seabridge, Aircraft Systems: Mechanical, Electrical and Avionics Subsystems Integration: Wiley, 2008.

[3] V. Madonna, P. Giangrande, and M. Galea, "Electrical Power Generation in Aircraft: review, challenges and opportunities," IEEE Transactions on Transportation Electrification, pp. 1-1, 2018.

[4] P. Wheeler and S. Bozhko, "The More Electric Aircraft: Technology and challenges," IEEE Electrification Magazine, vol. 2, pp. 6-12, 2014.

[5] V. Madonna, P. Giangrande, C. Gerada, and M. Galea. (2018, Thermal analysis of fault tolerant electrical machines for MEA applications. The Journal of Engineering. Available: http://digitallibrary.theiet.org/content/journals/10.1049/joe.2018.0040

S. Pugliese, R. A. Mastromauro, and S. Stasi, "270V/28V wide bandgap device-based $\mathrm{DAB}$ converter for more-electric-aircrafts: Feasibility and optimization," in 2016 International Conference on Electrical Systems for Aircraft, Railway, Ship Propulsion and Road Vehicles \& International Transportation Electrification Conference (ESARS-ITEC), 2016, pp. 1-6.

[7] D. Izquierdo, R. Azcona, F. J. L. d. Cerro, C. Fernández, and B. Delicado, "Electrical power distribution system (HV270DC), for application in more electric aircraft," in 2010 Twenty-Fifth Annual IEEE Applied Power Electronics Conference and Exposition (APEC), 2010, pp. 1300-1305.

[8] C. Spagnolo, S. Sumsurooah, C. I. Hill, and S. Bozhko. (2018, FINITE STATE MACHINE CONTROL FOR AIRCRAFT ELECTRICAL DISTRIBUTION SYSTEM. The Journal of Engineering. Available: http://digital-

library.theiet.org/content/journals/10.1049/joe.2018.0039

[9] İ. Kocaarslan and E. Çam, "Fuzzy logic controller in interconnected electrical power systems for load-frequency control," International
Journal of Electrical Power \& Energy Systems, vol. 27, pp. 542$549,2005 / 10 / 01 / 2005$.

[10] B. Tang, S. Yang, L. Wang, and H. Zhang, "Power priority algorithm in application to aircraft distribution network reconfiguration," in 2016 International Conference on Electrical Systems for Aircraft, Railway, Ship Propulsion and Road Vehicles \& International Transportation Electrification Conference (ESARSITEC), 2016, pp. 1-5.

[11] L. Xuesen, "Multi-behaviors Finite State Machine," in 2009 IEEE Youth Conference on Information, Computing and Telecommunication, 2009, pp. 201-203.

[12] D. Pederson. (25/05/2018). Finite State Machines : https://ptolemy.berkeley.edu/projects/embedded/research/hsc/class lee249/lectures/l4-FSM-CFSM.pdf.

[13] I. Moir and A. G. Seabridge, Military Avionics Systems (Aiaa Education): Amer Inst of Aeronautics $\backslash \&, 2006$.

[14] X. Giraud, H. Piquet, M. Budinger, X. Roboam, M. Sartor, and S. Vial, "Knowledge-based system for aircraft electrical power system reconfiguration," in Electrical Systems for Aircraft, Railway and Ship Propulsion (ESARS), 2012, 2012, pp. 1-6.

[15] A. Pnueli and R. Rosner, "On the synthesis of a reactive module," presented at the Proceedings of the 16th ACM SIGPLAN-SIGACT symposium on Principles of programming languages, Austin, Texas, USA, 1989.

[16] N. Piterman, A. Pnueli, and Y. Sa'ar, "Synthesis of reactive(1) designs," presented at the Proceedings of the 7th international conference on Verification, Model Checking, and Abstract Interpretation, Charleston, SC, 2006.

[17] A. Pnueli, "The temporal logic of programs," presented at the Proceedings of the 18th Annual Symposium on Foundations of Computer Science, 1977.

[18] H. Xu, "Design, Specification, and Synthesis of Aircraft Electric Power Systems Control Logic," Doctor of Philosophy Ph.D. thesis, Electrical engineering, California Institute of Technology, Pasadena, California, 2013.

[19] S. N. Motapon, L. A. Dessaint, and K. Al-Haddad, "A Comparative Study of Energy Management Schemes for a Fuel-Cell Hybrid Emergency Power System of More-Electric Aircraft," IEEE Transactions on Industrial Electronics, vol. 61, pp. 1320-1334, 2014. 